\section{Trisomy 9 Mosaicism with Multiple Congenital Anomalies*}

\author{
Summary. A nine-year-old male \\ with developmental abnormalities was \\ found to be mosaic for an extra No. 9 \\ chromosome $(46, \mathrm{XY} / 47, \mathrm{XY},+9)$. The \\ clinical findings included severe mental \\ retardation, peculiar facies, short stature, \\ hypotonia, dextroposition with a ventri- \\ cular septal defect, and patent ductus \\ arteriosus, as well as significant abnor- \\ malities of the brain.
}

As a result of the institution of new techniques for the identification of individual chromosomes, it is now possible to characterize certain gross chromosome abnormalities more precisely. This is particularly true for the $\mathrm{C}$ group where extra chromosomes have been observed, both with and without mosaicism, but have been difficult to categorize.

The patient described in this report was identified as a mosaic for trisomy 9 by the quinacrine mustard fluorescent banding technique, the major cell line being $46, \mathrm{XY}$ and the minor line $47, \mathrm{XY},+9$.

\section{Case Report}

J.C. (JHH 1096740 ), a nine-year-old male, was the fourth child of a 32-year-old mother and 40-year-old father. The union was non-consanguineous. The sibs are normal. A paternal uncle was reported to be severely retarded.

The pregnancy was of 39 weeks' duration and was complicated by three days of profuse vaginal bleeding during the 14th week of gestation. The fetal movements were diminished throughout the final trimester. The birth weight was $2.7 \mathrm{~kg}$ and the length $48 \mathrm{~cm}$. At the time of delivery, the infant had a weak cry and was lethargic and cyanotic.

The patient was noted to have many congenital anomalies (Table I). Hyperbilirubinaemia, secondary to AO incompatibility during the first day of life, necessitated a partial exchange transfusion. The peak serum bilirubin was $15 \mathrm{mg} \%$.

Cardiac examination at one month of age revealed a grade II harsh ejection murmur to both the left and right of the sternum, a right ventricular lift, and a loud pulmonic closure sound. The electrocardiogram

Received 20 March 1973.

* This work was supported in part through project 917, Maternal and Child Health Service, Department of Health, Education, and Welfare.

Reprint requests to Dr R. H. A. Haslam, The John F. Kennedy Institute, 707 North Broadway, Baltimore, Maryland 21205, USA.
TABLE I

CONGENITAL ANOMALIES OF THE PROPOSITUS

\begin{tabular}{ll}
\hline General & $\begin{array}{c}\text { Short stature, low-set ears, receding jaw, } \\
\text { high-arched palate, shield-like chest } \\
\text { Intermittent mottling, simian crease } \\
\text { Skin }\end{array}$ \\
$\begin{array}{l}\text { Microcephaly, occipital bossing } \\
\text { Silaterally dislocated hips and knees, } \\
\text { thoracic scoliosis } \\
\text { Bilateral undescended testicles and ingu- } \\
\text { inal hernias } \\
\text { Dextroposition, ventricular septal defect } \\
\text { Cardiovascular }\end{array} \quad \begin{array}{l}\text { and patent ductus arteriosus } \\
\text { Central nervous system } \\
\text { tonia, diminished deep tendon reflexes, } \\
\text { wide-based gait, bilateral ptosis, hydro- } \\
\text { cephalus, incomplete development of } \\
\text { temporal lobes }\end{array}$ \\
\hline
\end{tabular}

showed evidence of left ventricular prominence, and the chest radiograph demonstrated dextroposition.

Because of poor weight gain, frequent upper respiratory infections, intermittent cyanosis, and the abnormal cardiac findings, the child was admitted to the Johns Hopkins Hospital for investigation at five months of age. Cardiac catheterization demonstrated true dextroposition with a small bidirectional shunt at the ventricular level. The right ventricular pressure was at systemic levels. The pulmonary artery was not entered. Cineangiocardiography showed the right ventricle on the right, the left ventricle medially and to the left, and no evidence of pulmonic stenosis. The systemic arterial saturation was $85 \%$. The patient had frequent episodes of high fever and vomiting. Examinations of cerebrospinal fluid and blood cultures were negative. A cause for the pyrexia was never established.

He was readmitted to the Johns Hopkins Hospital at the age of two years for investigation of hypotonia. Motor nerve conduction velocity, electromyography, electroencephalography, and a muscle biopsy were normal. A quantitation of the urine amino acids and several screening tests for a variety of abnormal urinary metabolites failed to demonstrate an inborn error of metabolism. A chromosome analysis carried out at another hospital showed an abnormal karyotype which was originally interpreted as $\mathrm{XY} / \mathrm{XXY} / \mathrm{X}$ mosaicism.

The developmental milestones were significantly retarded. He did not sit unsupported until two, stood at three, and began to walk at five years of age. The first word occurred at six years. At age eight, the patient communicated primarily by gesture and had a vocabulary of six words. Psychological examination placed his intelligence in the severely retarded range.

The patient's final hospital admission was necessary for treatment of intractable congestive failure (Fig. 1). The failure progressed in spite of vigorous medical management. He died at nine years of age.

\section{Cytogenetic Investigation}

Chromosome analyses on the patient and his parents were performed on leucocyte preparations using a modification of Moorhead's system (Moorhead et al, 1960). Additional studies on the 

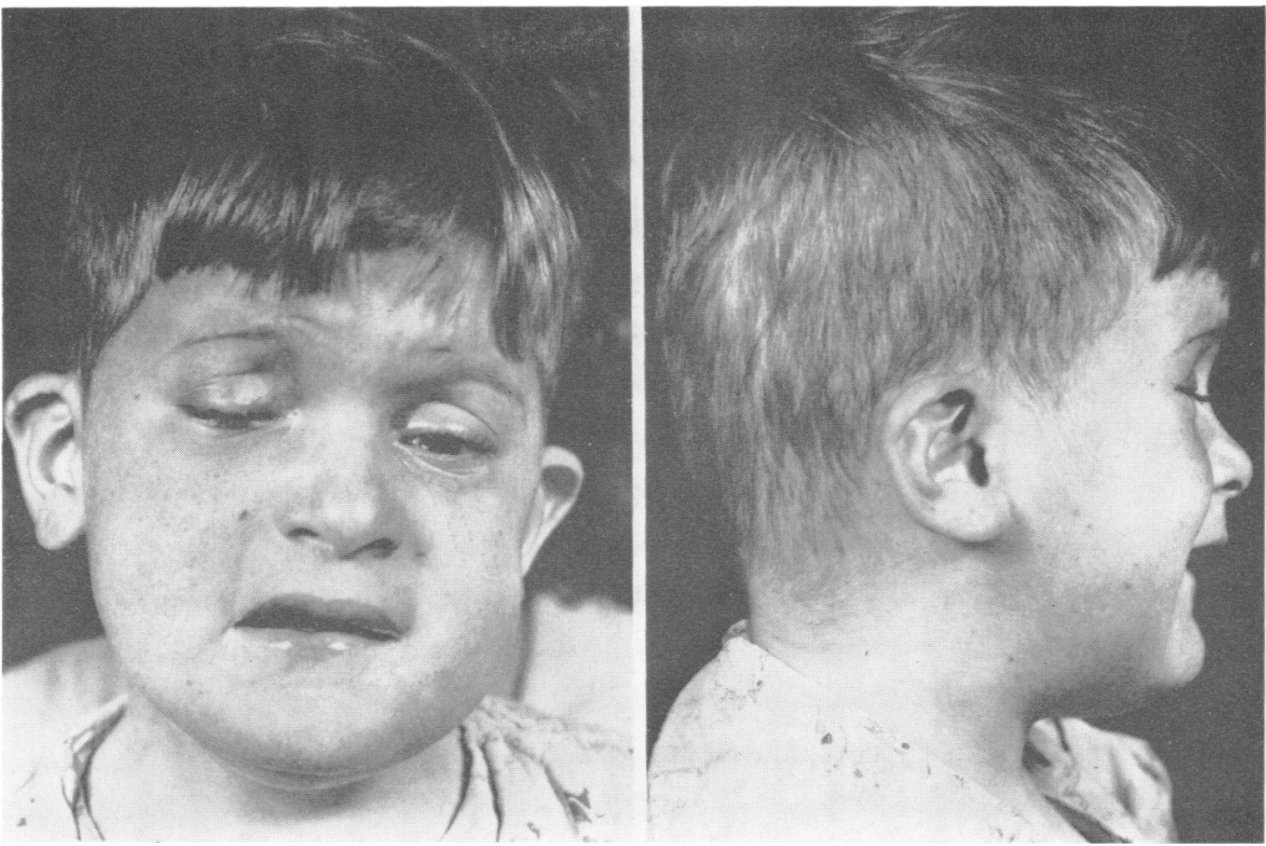

FIG. 1. AP and lateral view of the head of the propositus showing facial asymmetry and ptosis, low-set ears, relative micrognathia, and occipital prominence.

patient included examination of cultured skin fibroblast cells (Taylor et al, 1973). A modification of the method of Caspersson was utilized for the determination of the quinacrine mustard fluorescent patterns of the individual chromosomes (Caspersson et al, 1970; Moore, Heller, and Thomas, 1973).

Fifty fibroblast cells from the patient were stained in the conventional manner (aceto-orcein staining). Of these cells, 46 had a modal number of 46 chromosomes with the normal karyotype of a male. Four $(8 \%)$ were found which had 47 chromosomes. In each case, the extra chromosome appeared to be in the $\mathrm{C}$ group $(6-12+\mathrm{X})$. An analysis of the chromosomal complement of 63 leucocytes using the fluorescent banding technique also revealed four cells $(6 \%)$ with 47 chromosomes, while the remaining 59 had a modal number of 46 with normal banding patterns.

In each of the four cells with 47 chromosomes, the fluorescent patterns were consistent with the presence of an extra number 9 chromosome (Fig. 2), Barr body determinations of buccal smears on several occasions were negative.

Fifty leucocytes were analysed from each of the parents. The karyotypes appeared normal with aceto-orcein staining. None of the cells observed had 47 chromosomes.

\section{Necropsy Examination}

A partial necropsy included examination of the heart and brain. The heart was massively enlarged because of dilatation and hypertrophy of the ventricles. A small ductus arteriosus connected the proximal left pulmonary artery and the aorta distal to the origin of the left subclavian artery. There was a $1.0 \mathrm{~cm}$ defect in the muscular portion of the ventricular septum.

Gross examination of the brain showed several anomalies, the most striking of which included an enlarged cisterna magna, small temporal lobes with incomplete operculization, widening of the sylvian fissures, marked enlargement of the third and lateral ventricles with subependymal sclerosis, and minimal arachnoidal thickening, most prominent over the superior cerebellum and the parasagittal region of the hemispheres (Fig. 3). Microscopic examination failed to demonstrate significant abnormalities.

\section{Discussion}

Complete trisomy of any of the C-group autosomes appears to be a very infrequent occurrence, there being few reported cases at the present time (Jalbert et al, 1966; Juberg, Gilbert, and Salisbury, 1970; Caspersson et al, 1972). Cytogenetic 


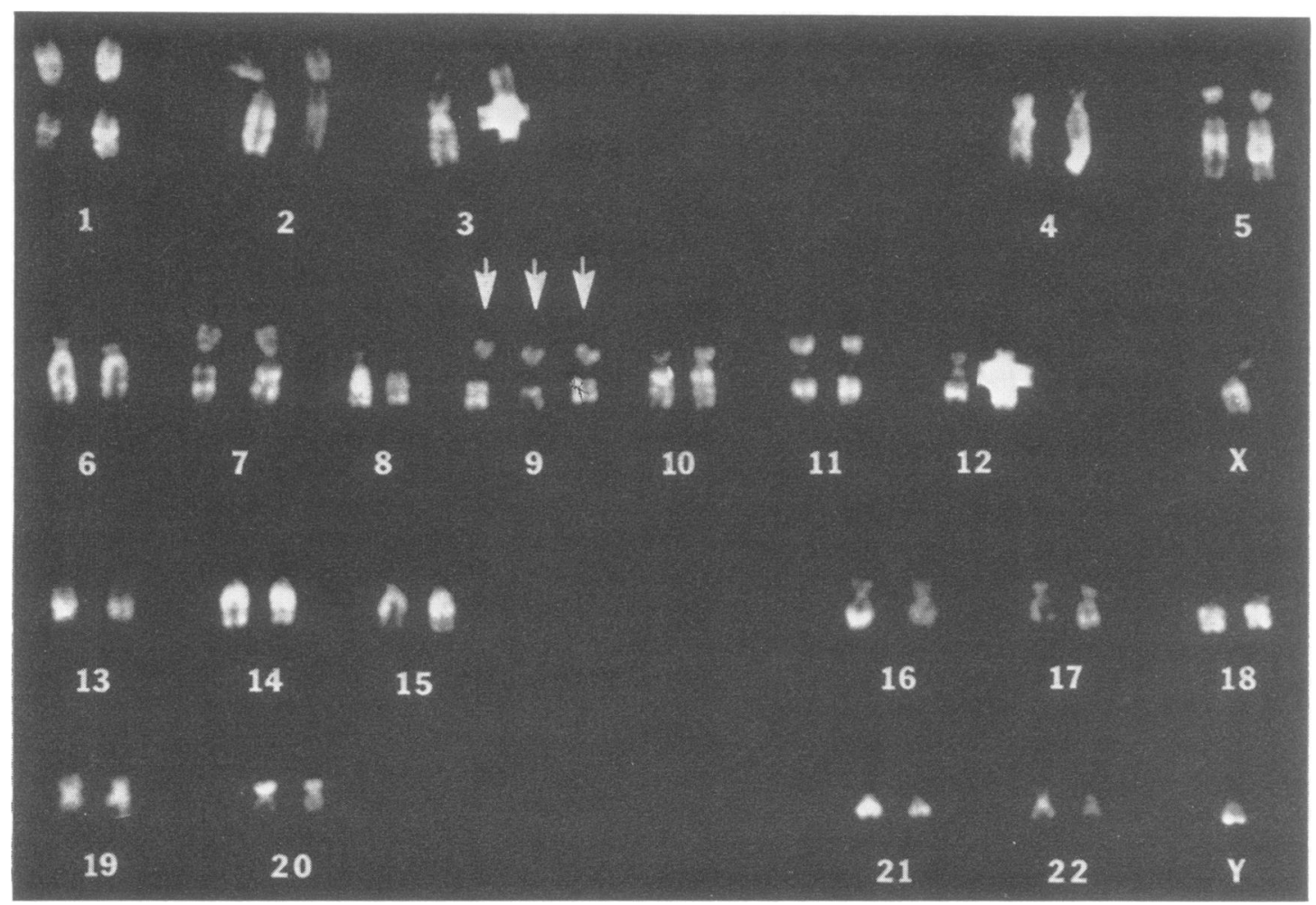

FIG. 2. Karyotype of the propositus demonstrating an extra No. 9 chromosome by the quinacrine fluorescent technique (arrows).

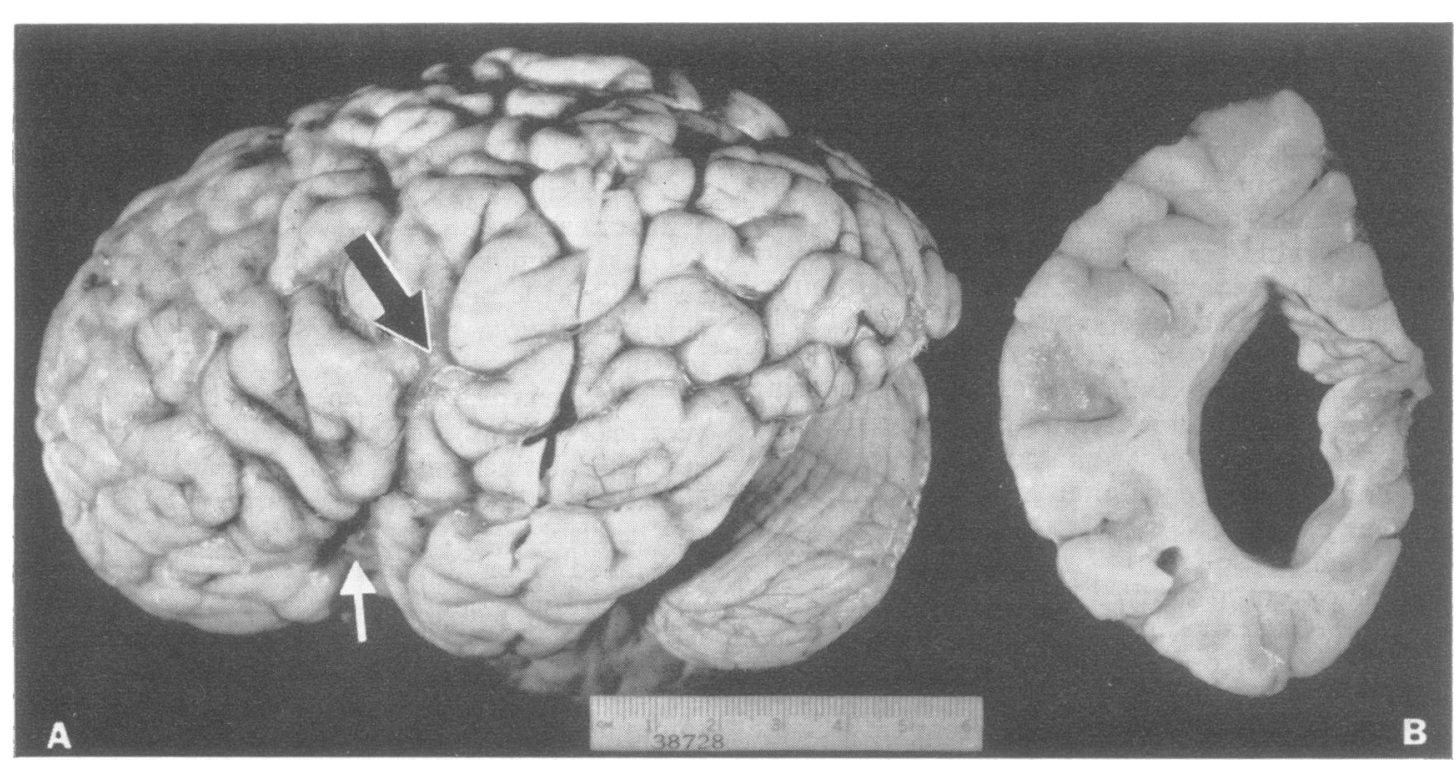

Fig. 3. A. Lateral surface of the left cerebral hemisphere and cerebellum. The brain is small, the frontal operculum is incomplete (white arrow), and the sylvian fissure has an abnormal vertical orientation (black arrow). B. Coronal section of the occipital lobe showing enlargement of the lateral ventricle. 
investigation of spontaneous abortions suggests that this low incidence may be the result of increased fetal wastage generally associated with the trisomy of large autosomes (Kuliev, 1971).

However, there have been frequent reports of patients who were mosaic with both a normal cell line as well as a line trisomic for an extra chromosome in the $\mathrm{C}$ group. The clinical manifestations of these patients have been extremely varied.

In this group was a normal woman in whom two of three pregnancies resulted in severe congenital anomalies (Stolte, Evers, and Blankenborg, 1964), a patient with amenorrhoea (Jacobs et al, 1961), individuals with haematological disorders (de la Chapelle et al, 1970), and a larger number of patients with a series of developmental abnormalities. Included in this latter group are two children with mild retardation, short stature, and anomalies of the genitourinary tract and skeletal system (Riccardi, Atkins, and Holmes, 1970). More commonly, severe mental retardation, malformations of the central nervous system, genitourinary tract, and skeleton have been noted (El-Alfi, Powell, and Biesele, 1963; Stalder, Buhler, and Weber, 1963; Wolf and Reinwein, 1965; Bargman et al, 1967; Gustavson, Hagberg, and Santesson, 1967; Higurashi et al, 1969).

It has been suggested that this clinical divergence could be the result of several factors, including the involvement of different C-group chromosomes, diverse degrees of mosaicism, and differences in involved tissues (Gustavson et al, 1967; Caspersson et al, 1972). With the advent of new identification techniques (Caspersson et al, 1970), it is possible to eliminate one of these variables, namely, the identity of the extra chromosome.

With this advance, it is reasonable to anticipate that several new syndromes should emerge, each associated with the trisomic state of a particular Cgroup chromosome. Evidence that this will indeed be the case is suggested by the recent description of at least four (Caspersson et al, 1972) and perhaps five patients with trisomy 8 (de Grouchy, Turleau, and Leonard, 1971).

The patient described herein is believed to be mosaic for trisomy 9. The outstanding anomalies include severe mental retardation, peculiar facies, short stature, hypotonia, dextroposition of the heart with a ventricular septal defect and patent ductus arteriosus with evidence of bidirectional shunting, and increased pulmonary vascular resistance from an early age. The gross examination of the brain was striking. The hydrocephalus and abnormalities of the temporal lobes are consistent with a developmental anomaly rather than a postinfectious process.
We are unaware of any previous patients for which there exists direct evidence for the presence of a trisomic 9 cell line, complete or mosaic. We do feel, however, that additional patients will be described and that it may then be possible to determine if the trisomic state for this chromosome is characteristically associated with the clinical findings of the type found in this patient.

The authors are indebted to Dr Victor A. McKusick and $\mathrm{Dr}$ Joan L. Gerring for their suggestions and helpful criticism of the manuscript; and to Drs Donald L. Price and Richard R. Graham for reviewing the necropsy. We thank Mrs Lorraine Michel for manuscript preparation and Dr Samuel Southard for referring the patient.

Robert H. A. Haslam, Stuart P. Broske, Charleen M. Moore,* George H. Thomas, and Catherine A. Neill

Departments of Pediatrics, Neurology, and Medicine, The Fohns Hopkins School of Medicine and The fohn F. Kennedy Institute, Baltimore, Maryland, USA

REFERENCES

Bargman, G. J., Neu, R. L., Kajii, T., Leāo, J. C., and Gardner, L. I. (1967). Trisomy C mosaicism in a seven month old girl. Humangenetik, 4, 13-17.

Caspersson, T., Lindsten, J., Zech, L., Buckton, K. E., and Price, W. H. (1972). Four patients with trisomy 8 identified by the fluorescence and giemsa banding techniques. Fournal of Medical Genetics, 9, 1-7.

Caspersson, T., Zech, L., Johansson, C., and Modest, E. J. (1970). Identification of human chromosomes by DNA-binding fluorescent agents. Chromosoma, 30, 215-227.

Chapelle, A. de la, Wennström, J., Wasastjerna, C., Knutar, F. Stenman, U.-H., and Weber, T. H. (1970). Apparent C trisomy in bone marrow cells, report of two cases. Scandinavian fournal of Haematology, 7, 112-122.

De Grouchy, J., Turleau, C., and Leonard, C. (1971). Etude en fluorescence d'une trisomie $C$ mosaique probablement $8: 46, X Y$ / 47,XY, ?8+. Annales de Génétique, 14, 69-72.

El-Alfi, O. S., Powell, H. C., and Biesele, J. J. (1963). Possible trisomy in chromosome group 6-12 in a mentally retarded patient. Lancet, 1, 700-701.

Gustavson, K.-H., Hagberg, B., and Santesson, B. (1967). Mosaic trisomy of an autosome in the 6-12 group in a patient with multiple congenital anomalies. Acta Paediatrica Scandinavica, 56, 681686.

Higurashi, M., Naganuma, M., Matsui, I., and Kamoshita, S. (1969) Two cases of trisomy C6-12 mosaicism with multiple congenital malformations. Fournal of Medical Genetics, 6, 429-434.

Jacobs, P. A., Harnden, D. G., Buckton, K. E., Court Brown, W. M., King, M. J., McBride, J. A., MacGregor, T. N., Maclean, N., Fotheringham, A., and Isdale, M. (1961). Cytogenetic studies in primary amenorrhoea. Lancet, 1, 1183-1188.

Jalbert, P., Jobert, J., Patet, J., Mouriquand, C., and Roget, J. (1966). Un nouveau cas de trisomie présumée 6-12. Annales de Génétique, 9, 109-112.

Juberg, R. C., Gilbert, E. F., and Salisbury, R. S. (1970). Trisomy $\mathrm{C}$ in an infant with polycystic kidneys and other malformations. Fournal of Pediatrics, 76, 598-603.

Kuliev, A. M. (1971). Cytogenetic investigation of spontaneous abortions. Humangenetik, 12, 275-283.

* Present address: Department of Pediatrics, University of Texas Medical School at Houston, Freeman Building, Texas Medical Center, Houston, Texas 77025, USA. 
Moore, C. M., Heller, R. H., and Thomas, G. H. (1973). Developmental abnormalities associated with a ring chromosome 6 . fournal of Medical Genetics, 10. (In press.)

Moorhead, P. S., Nowell, P. C., Mellman, W. J., Battips, D. M., and Hungerford, D. A. (1960). Chromosome preparations of leukocytes cultured from human peripheral blood. Experimental Cell Research, 20, 613-616.

Riccardi, V. M., Atkins, L., and Holmes, L. B. (1970). Absent patellae, mild mental retardation, skeletal and genitourinary anomalies, and $\mathrm{C}$ group autosomal mosaicism. Fournal of Pediatrics, 77, 664-672.

Stalder, G. R., Buhler, E. M., and Weber, J. R. (1963). Possible trisomy in chromosome group 6-12. Lancet, $1,1379$.

Stolte, L., Evers, J., and Blankenborg, G. (1964). Possible trisomy in chromosome group 6-12 in a normal woman Lancet, 2., $480-481$.

Taylor, H. A., Thomas, G. H., Miller, C. S., Kelley, T. E., and Siggers, D. (1973). Mucolipidosis 111 (pseudo-Hurler polydystrophy): cytological and ultrastructural observations of cultured fibroblast cells. Clinical Genetics. (In press.)

Wolf, U. and Reinwein, H. (1965). Chromosomenmosaik Ctrisomie/normal. Humangenetik, 1, 686-687.

\section{A Case of Trisomy 9}

Summary. The first patient with trisomy 9, an infant who survived 28 days, is reported. Clinical findings included microcephaly, low-set malformed ears, small palpebral fissures, enophthalmos, bulbous nose, micrognathia, low hairline, congenital heart disease, skeletal abnormalities, small penis, hypoplastic scrotum, and a Dandy-Walker like deformity of the fourth ventricle.

Although there are numerous reports of an extra chromosome in the $\mathrm{C}$ group, identification of the additional chromosome as a No. 9 has not been demonstrated. The purpose of this report is to document the first example of trisomy 9.

\section{Case Report}

A male infant was admitted to the Boston Floating Hospital for Infants and Children at the age of 2 days because of multiple congenital anomalies. He was the product of a 40 -week gestation of a normal 24-year-old gravida 2, para 2, female and a 25 -year-old male. Birth weight was $3218 \mathrm{~g}$. During the first and second trimesters the mother had severe nausea with vomiting as well as vaginal spotting, bronchitis, and sinusitis. There was no known exposure to irradiation or infectious diseases. During the pregnancy the mother received the following medications: Erythromycin, Percogesic

Received 17 January 1973 (phenyltoloxamine and acetaminophen), Compazine (prochlorperazine), Bendectine (dicyclomine hydrochloride, dexylamine succinate, and pyridoxine hydro-
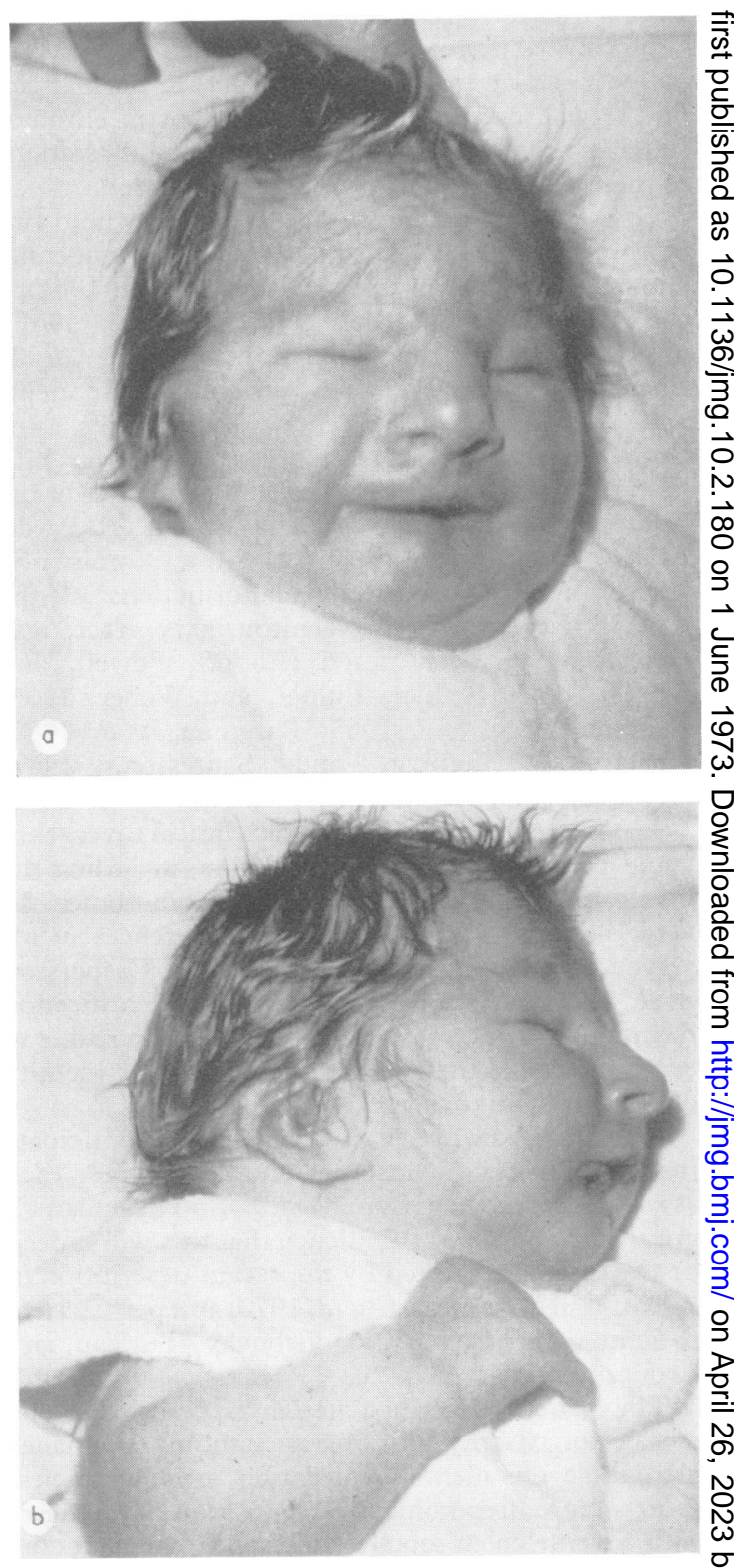

FIG. 1a and 1b. Front and side views of the face showing small palpebral fissures, bulbous nose, low-set and abnormally shaped ears, and micrognathia. 